\title{
Performance Evaluation of Health Insurance: Ways for Winning Confidence
}

\author{
Kiranmayi.V ${ }^{1}$, Dr. Suresh Naik. $\mathbf{2}^{\mathbf{2}}$ \\ ${ }^{1,2}$ Senior Faculty, Institute of Insurance and Risk Management, Hyderabad, India
}

\begin{abstract}
Health is a fundamental force that decides the overall quality of human life. The health of the population is a vital and essential issue for any country. The new National Health Policy of India (2017) emphasizes the growing burden of non- communicable diseases and corresponding growing expenditure. Indian Government announced the world's most massive health scheme, the Ayushman Bharat Yojana, in 2018, which is a significant step towards attaining universal health coverage in India. This scheme provides a cover of Rs.5 lakh per family per year for various medical procedures. Although India's Government is taking many such initiatives to improve public health, a lot more needs to be done to attain universal coverage. Out of pocket expenditure paid by individuals towards health care in India ranges at a high percentage over the years. Although health insurance premium has shown an increase over the years, there is no drop in this expenditure. This study shows the phenomenal growth achieved by health insurance, specifically after privatization, premium growth, and improvement in claims ratios. It is suggested that the insurance companies should modify the coverage of health insurance policies so that the uncovered expenses are reimbursed during hospitalization. Insurance companies also should shift their focus towards wellness instead of covering sickness to keep their businesses sustainable in the long run.
\end{abstract}

Keywords

Health Insurance; Out-Of-Pocket Expenditure (OOP); Incurred Claims Ratios; Wellness Concept

\section{Introduction}

India is one of the fastest-growing economies in the world. Due to robust growth, India was able to bring down the poverty level over a period of time from 45.3 percent in 1993 to 22.8 percent in $2018^{\mathrm{i}}$. Further increase in the per capita income necessitated better health facilities, and as a result, the average Indian life expectancy increased consistently from 33.94 in 1950 to 69.41 in $2016^{\mathrm{ii}}$. Providing standard public health care is always a big challenge for such a hugely populated country, with increased average life expectancies. Sixty percent of hospitals and 80 percent of doctors are located in urban areas serving only 28 percent of the population (KPMG and OPPI, 2016), whereas around $69 \%$ of India's population resides in rural areas. This makes it hard for rural people to access health care compared to those who live in urban areas. It is required for a growing economy to provide better healthcare facilities across the country, including rural areas.

According to Article 47 of the Indian Constitution, every State is responsible for 'raising the level of nutrition,' 'standard of living of people' and 'improvement of public healthcare' as among its primary duties. In the absence of a standard health scheme covering the entire population, the private health sector is the dominant player responsible for providing most healthcare in India (Mahapatro, Singh, \& Singh, 2018). The Fastpaced life, high level of pollution, sedimentary lifestyle, and unhealthy diet are leading causes of significant health disasters in India. Such lifethreatening diseases are pushing millions of Indians into below poverty, as they are spending a substantial portion of their earnings on these medical emergencies. An increase in life expectancy and chronic diseases increased morbidity and health expenditure (Jayakrishnan T, Jeeja MC, 2015).

A substantial portion of the population spends on outpatient visits from their savings, whereas, for inpatient care, people rely on other alternative sources of financing such as borrowings, sale of assets, and contribution from friends, due to the severity of the diseases (Sangar, Dutt, \& Thakur, 2019). Government and private health insurance plans certainly rescue individuals from catastrophic health risks and bring down their burden of out of pocket expenses. For example, Rajiv Arogya Scheme (RAS) in Andhra Pradesh in 2007 for below poverty line people has led to a significant decline in OOP spending and borrowing finance for inpatient care (Sangar et al., 2019). Increased health expenditure, combined with a lack of universal healthcare policy in India, forces the Indian public to look for alternative 
options, such as health insurance. This will undoubtedly decrease the incidence of large outof-pocket medical expenditures and reduce Government spending on health care needs. In India, until 2000, health insurance is an underdeveloped and less significant segment. After the privatization of Insurance, it has emerged as a tool to manage people's financial needs with many improvements. At this juncture, understanding health insurance's growth is significant to facilitate the segment's future direction.

\section{Review of Literature:}

Health insurance can be considered an important tool to reduce the out of pocket expenditure for most of India's population. Due to India's nonavailability of a universal health insurance policy, the OOP expenditure is very high compared to other developed countries. As per World Bank data (2016), $64.6 \%$ of India's total health expenditure is borne by the individuals/households as 'Out of Pocket Expenditure.' Massive spending on health may reduce consumption expenditure on other goods and services and push families into poverty (Joglekar, 2008). For the low and middle-income groups, savings from income remain the first option to overcome OOP expenditure (Mahapatro, 2018; Joglekar, 2008; Sagar et al. (2016).

Over a while, lack of confidence in a public health care facility has dragged low and middle-income groups towards private health care facilities; thus, the OOP expenditure is increasing from time to time (Mahapatro,2018). Further, OOP spending pushes approximately $3.5 \%$ to $6.2 \%$ of India's population below the poverty line every year (Grag and Karan, 2009). Many studies have also shown that coverage is available only for inpatient expenses in the majority of state government health insurance schemes. The schemes will not be reimbursing medicine diagnostic tests, attendant charges, physiotherapy, personal medical appliances, blood, oxygen, etc.(Key Indicators of Social Consumption in India: Health, 2017). Even after the implementation of Rashtriya Swasthya Bima Yojana (RSBY), the level of Outpatient expenditure remained the same as it is neglected by both public and private health insurance schemes (Anup Karan et al. (2017). As a result, OOP expenditure on health remains unchanged though there is a significant increase in health insurance premiums that reached Rs. 50,834 crores (IRDAI, 2018-19).

India has achieved a lot in the recent past in terms of health insurance. However, it is still a highly underdeveloped and less significant segment than fast-developing countries like China, Vietnam, and Sri Lanka (Anita, 2010). Indian Health insurers are trying hard to develop the segment by increasing business volumes. Private insurers have played a crucial role in spreading market share than government-owned companies (Chennappa, 2015). The emergence of standalone health insurance companies with the implementation of new technologies changing Indian health insurers' direction. The new technologies, such as Robotic Process Automation and Artificial Intelligence (AI), help insurers improve operational efficiency and enhance customer Experience(Capgemini, 2019).

Further, these technologies also help industry control fraudulent claims by automatizing services (Maitra, 2017). Additionally, insurance companies should partner with health care providers for offering wellness benefits and OP coverages at discounted prices to provide growth at a much faster pace in the coming years (KPMG and FICCI, 2017). This paper attempts to give an overview of health insurance's progress in India and throw light on specific areas through which insurers can win customers' confidence.

\section{Objectives:}

This writeup mainly focuses on providing information on Indian Health Insurance Market. The paper includes the Players, Growth of Health Insurance Premium, and Incurred Claims Ratios over the last two decades in India.

- To analyze health insurance premium growth over the years and comparatively the claims ratios.

- To understand the aspects of recent technology interventions and wellness, this will drive the future of Indian Health Insurance.

For this study, data has collected from IRDAI Annual Reports during 2001-2019 on Health insurance. Insurance data has been collected on Out of Pocket Expenditure towards healthcare from the World Bank Database from 2000 to 2016 of selected countries and compared to India to understand its need. The Paper analyses the data 
of premium contributions by various insurance companies offering health insurance policies.

\section{Status of Out of Pocket Expenditure and Health Insurance in India}

The share of the amount allocated towards health care for a country is decided by its political, economic, social, and demographic attributes. These factors are unique and vary from country to country. Healthcare expenditures are largely Out Of Pocket (OOP) in India, as the budget allocated to health remains one of the lowest in the world. (Ahlin, Nichter, \& Pillai, 2016). According to the World Bank, in India, the total expenditure on health as a proportion to GDP in 2017 was $3.6 \%$, whereas the world average is $10.02 \%$. From 2009 to 2018 , there is not much variation in the percentages of GDP's total health expenditure. It ranged being highest at 3.75 in 2013-14 and lowest at 3.2 in 2011. The share of public spending is between 30 to 35 percent. Out of pocket expenditure by the individual ranged from 65 to 70 percent over these years (Figure 1).

Out Of Pocket (OOP) expenditure is a crucial indicator of financial protection and highlights the private engagement position necessary for health financing. Among various finance sources, savings from income remain the first option to cope with Out Of Pocket Expenditure on health for most Indian populations. Such high Out-OfPocket expenses push $7 \%$ of the population into poverty each year(Joglekar, 2008). The size of OOP expenditure going towards health care in India is worrying. From 2000 to 2016, OOP payments in India have averaged around $69 \%$ of total healthcare expenditures. Although the OOP had decreased from $71.7 \%$ in 2000 to $64.6 \%$ in 2016 , it is still higher than in many countries globally.

\begin{tabular}{|c|c|c|c|}
\hline \multicolumn{3}{|c|}{ Table:1: Health Expenditure in India (\% GDP) } \\
\hline Years & $\begin{array}{c}\text { Public } \\
\text { Expenditure } \\
\text { on Health } \\
\text { (\% GDP) }\end{array}$ & $\begin{array}{c}\text { OOP } \\
\text { Expenditure } \\
\text { on Health } \\
\text { (\% GDP) }\end{array}$ & $\begin{array}{c}\text { Total Health } \\
\text { Expenditure } \\
\text { (\% GDP) }\end{array}$ \\
\hline $2009-10$ & 1.12 & 2.36 & 3.48 \\
\hline $2010-11$ & 1.07 & 2.20 & 3.27 \\
\hline $2011-12$ & 1.10 & 2.15 & 3.25 \\
\hline $2012-13$ & 1.09 & 2.24 & 3.33 \\
\hline $2013-14$ & 1.00 & 2.75 & 3.75 \\
\hline $2014-15$ & 0.98 & 2.64 & 3.62 \\
\hline $2015-16$ & 1.02 & 2.58 & 3.6 \\
\hline $2016-17$ & 1.17 & 2.49 & 3.66 \\
\hline $2017-18$ & 1.28 & 2.32 & 3.6 \\
\hline
\end{tabular}

Source: National Health Profile - 2018 and World Bank Data

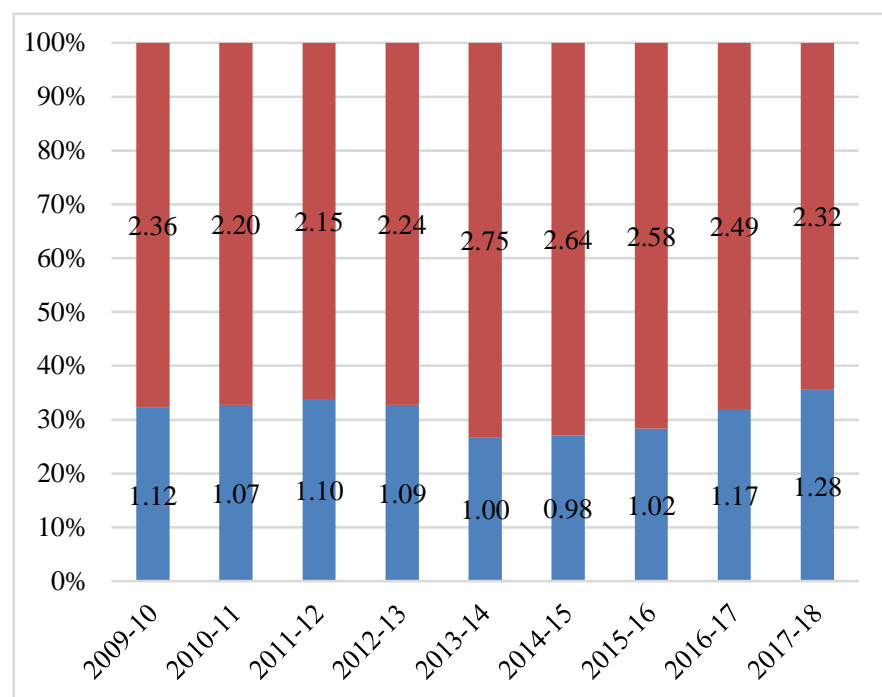

- OOP Exp on Health (\% GDP) $\square$ Public Expenditure on Health (\% GDP)

Figure 1. Public Vs Out of Pocket Expenditure of GDP

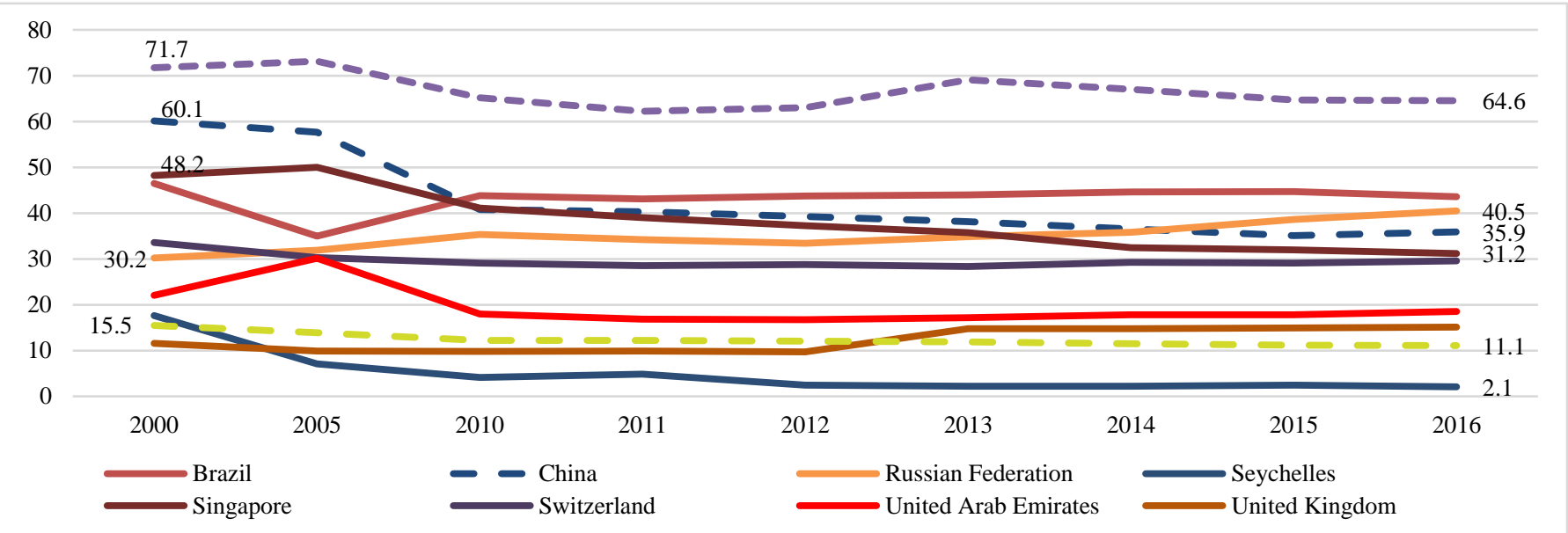

Figure 2. Public Vs. Out of Pocket Expenditure of GDP

Source: World Bank, 2016, last updated on 27-02-2020 
Among the countries that made significant progress in reducing OOP expenditure China, Singapore, and Seychelles made noticeable efforts. China is able to reduce the out of pocket expenditure from $60.1 \%$ in 2000 to $35.9 \%$ in 2016. Singapore is also able to decrease from $48.2 \%$ in 2000 to 31.2 gradually. In 2016, Seychelles almost brought it to the lowest, i.e., 2.1 $\%$ in 2016. In countries like Brazil, Switzerland, and UAE, the percentages are not much varied, and they were able to reduce only 3 to $4 \%$ over 15 years. Both in Russia and the United Kingdom, the percentage has increased from 30.2 in 2005 to $40.5 \%$ in 2016 and 11.6 to $15.1 \%$, respectively. The United States has always been very focused on healthcare spending; hence the percentage of Out Of Pocket expenditure was maintained at a low rate over all the years.

Health insurance is a security mechanism to the individual's savings in hospitalization by providing reimbursement of medical expenses. It is a one-year renewable contract between the policyholder and the insurance provider. These days, health insurance is a necessity rather than an option because of medical inflation and the increasing burden of emerging diseases on the population. As per World Bank data, 2019, India's total population is 1.376 billion; by this, it is estimated that approximately $34 \%$ of India's total population is covered under any of the health insurance policies. The number of lives covered under health insurance policies during FY 201819 is Rs.47,210 crores(IRDAI, 2018-19)

Indian health insurance is a mixture of Government sponsored schemes (26\%) and Private health insurance policies (8\%), as depicted in Figure 3. Private health insurance policies are predominantly sold by non-life insurance companies, including standalone health insurance companies that exclusively deal with health portfolios.

\begin{tabular}{|l|l|l|l|l|l|}
\hline \multicolumn{6}{|c|}{ Table:2: No. of lives covered in '000s } \\
\hline Years & $\mathbf{2 0 1 5}$ & $\mathbf{2 0 1 6}$ & $\mathbf{2 0 1 7}$ & $\mathbf{2 0 1 8}$ & $\mathbf{2 0 1 9}$ \\
\hline Government & 2143 & 2733 & 3350 & 3593 & 3571 \\
\cline { 2 - 6 } Business & $74 \%$ & $76 \%$ & $77 \%$ & $74 \%$ & $76 \%$ \\
\hline \multirow{2}{*}{$\begin{array}{l}\text { Group } \\
\text { Business }\end{array}$} & 483 & 570 & 705 & 894 & 729 \\
\cline { 2 - 6 } & $17 \%$ & $16 \%$ & $16 \%$ & $19 \%$ & $15 \%$ \\
\hline \multirow{4}{*}{ Individual } & 254 & 287 & 320 & 333 & 421 \\
\cline { 2 - 6 } & $9 \%$ & $8 \%$ & $7 \%$ & $7 \%$ & $7 \%$ \\
\hline Total & 2880 & 3591 & 4375 & 4820 & 4721 \\
\hline
\end{tabular}

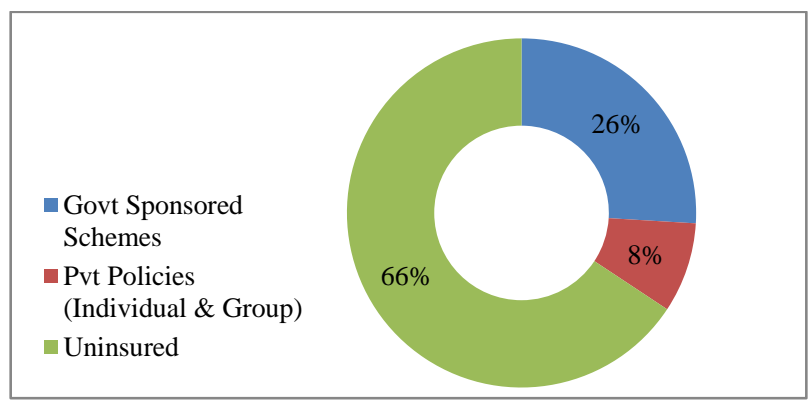

Figure 3. Coverage of Health Insurance in India

Source: IRDAI Annual Report (2018-19) and

World Population Prospects (2020)

As of June 2020, 59 insurance companies are licensed by IRDAI for doing insurance business in India. Of these companies, 24 are life insurance companies, 34 are non-life insurance companies, including two specialized institutions and one reinsurance Company other than the specialized institutions. All other companies deal with health plans. Star Health and Allied Health Insurance Company Limited is the first standalone health insurance company to be granted a license by IRDAI in 2006.

\begin{tabular}{|c|c|c|c|c|}
\hline \multicolumn{5}{|c|}{ Table 3: Details Of Indian Insurers Dealing With Health Insurance Products } \\
\hline Sl.No & $\begin{array}{l}\text { Insurance } \\
\text { Companies }\end{array}$ & Details & Type of health plans offered & Remarks \\
\hline 1 & Life Insurance & $\begin{array}{l}\text { Public Sector }-1 \\
\text { Private Sector - } 23 \\
\text { Total - } \mathbf{2 4}\end{array}$ & $\begin{array}{l}\text { Riders benefits* } \\
\text { Hospital cash benefit plans } \\
\text { Specific disease plans (Cancer, } \\
\text { Heart, diabetes, etc.) }\end{array}$ & $\begin{array}{l}\text { Cannot offer indemnity** } \\
\text { based products as per the } \\
\text { Regulatory directions, } 2016\end{array}$ \\
\hline 2 & $\begin{array}{l}\text { Non-life } \\
\text { Insurance }\end{array}$ & $\begin{array}{l}\text { Public Sector }-6 * * * \\
\text { Private Sector }-21 \\
\text { Private Stand-Alone } \\
\text { Health Insurers }-7 \\
\text { Total - } 34\end{array}$ & $\begin{array}{l}\text { Indemnity based health plans } \\
\text { Hospital cash benefit plans } \\
\text { Critical illness plans } \\
\text { Travel insurance } \\
\text { Personal accidental plans } \\
\text { Specific disease plans }\end{array}$ & $\begin{array}{l}\text { Standalone health insurers are } \\
\text { dealing only with health } \\
\text { products licensed from the } \\
\text { year } 2006 \text { onwards by IRDAI }\end{array}$ \\
\hline
\end{tabular}




\begin{tabular}{|l|l|l|l|l|}
\hline 3 & Reinsurance & $\begin{array}{l}\text { Public Sector -1 } \\
\text { Foreign Branches - 10 }\end{array}$ & $\begin{array}{l}\text { General Insurance Corporation of } \\
\text { India (GIC Re) }\end{array}$ & $\begin{array}{l}\text { Supports all the primary } \\
\text { insurers in the event of huge } \\
\text { risks. }\end{array}$ \\
\hline
\end{tabular}

*Riders are available with Life insurance plans by paying an additional amount of premiums

**life insurance companies are offering only benefit plans.

***list includes two specialized institutions, namely, Agriculture Insurance Company of India Ltd and ECGC ltd.

\subsection{Analysis of Health Insurance Premium}

Health insurance is a growing segment, and it has reported growth of more than $17 \%$ in premium collection consistently for the past three years. In the latest annual report of IRDAI, the total premium collection grew to Rs.50834 crores in 2018-19 from Rs.41981 crores in 2017-18, registering a growth of 21.09 percent (IRDAI, 2017-18). The premium includes pure health products and health-related products offered through Personal Accident \& Travel Insurance segments. The health segment's market share has increased to 30 percent from 27.86 percent of the previous year. Health insurance is the second dominant portfolio in the non-life segment next to motor insurance and other lines of non-life products in India. The share of each segment is indicated in the following chart.

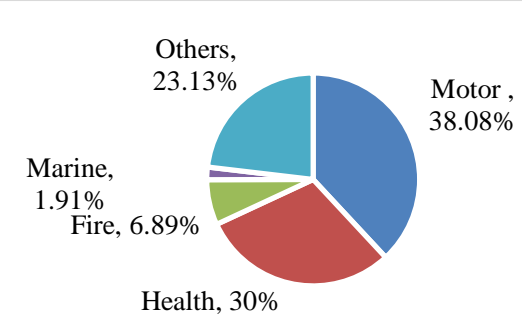

Figure 4. Premium contribution by various non-life segments

Source: IRDAI Annual Report, 2018-19

\subsection{Premium growth over the years}

In India, Insurance was privatized in the year 2000. Since then, with the entry of private players and the Indian Insurance Regulator's proactive role, health insurance has been rapidly growing. It is observed from Figure 4 that health insurance premiums substantially increased to Rs.44 873 crores in 2018-19 from Rs.761 crores in 2001.

Voluntary Mediclaim policy was introduced in India by the General Insurance Corporation of India (GIC) in 1986. However, till 2002, due to low awareness and lack of innovation in the products, the health insurance premium collection was meager. From the year 2003, the premium growth was very impressive; it increased from $32 \%$ to $59.7 \%$ in 2008 , which is the highest after privatization. The increased popularity of health insurance, the introduction of various plans, and the enhancement of existing plans are the critical factors that contributed to this growth (Shah, 2014).

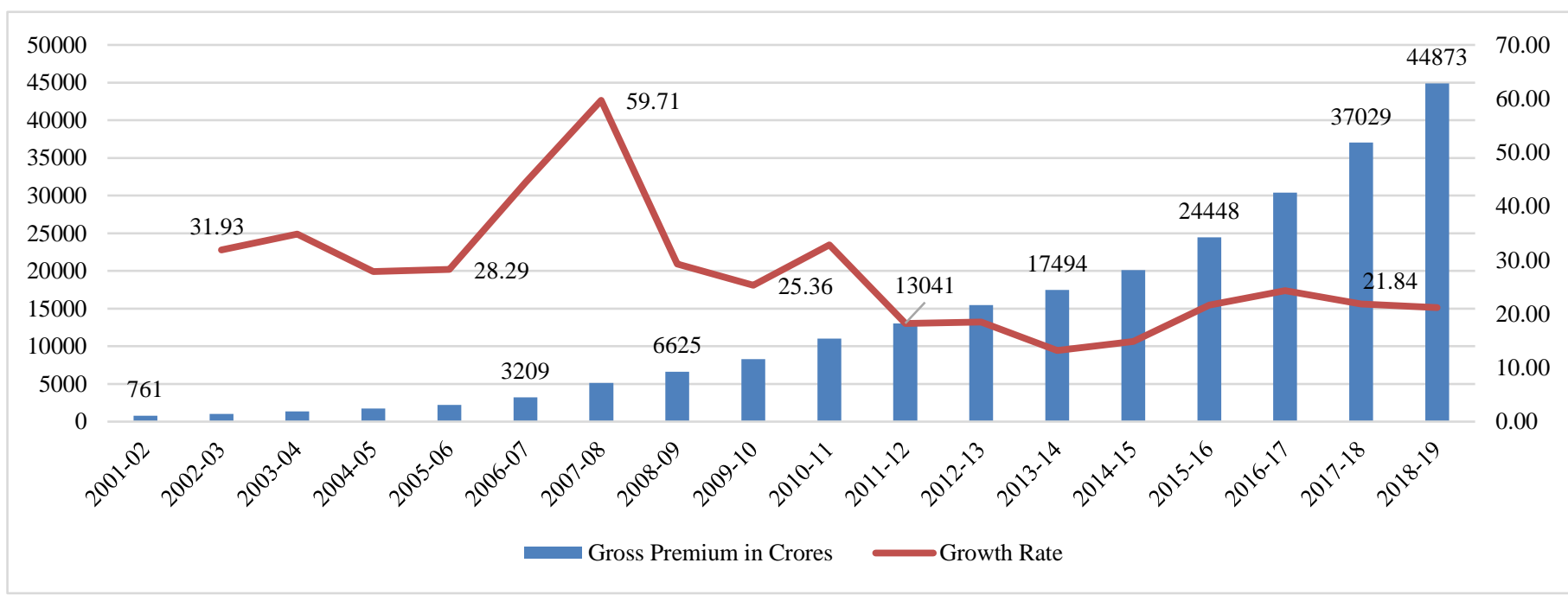

Figure 5. Growth Rate of Health Insurance over the years

Source: IRDAI Annual Reports (2001 - 2019), Note: Excluding Travel and Personal Accident Premiums 
During 2007-08, the industry witnessed two standalone health insurers viz., Star Health and Allied Insurance Company and Apollo DKV Health Insurance Company (now Apollo Munich). During 2009-2015, the Indian Insurance regulator took various initiatives circulars on Renewability, Senior Citizen's products, the introduction of free look period, and portability options in the health insurance area triggered steady growth in the premium from Rs.6625 crores to Rs. 20096 crores. Further, guidelines on standardization of various terms and forms also helped in driving business growth. As a result, standalone insurers' share increased from $12 \%$ to $16 \%$ (IRDAI, 2018-19).

From 2016 onwards, enhanced coverages offered by insurers including diseases like Parkinson's and
Alzheimer's, the introduction of double and triple covers for specified covers of Personal Accident Policies, coverage offered for vaccinations and pre and post-hospitalization expenses, waiver in waiting and survival periods, reduction in the list of exclusions, the introduction of top-up and surplus covers, initiation of reimbursement of donor expenses and Ayush treatments, new coverages for growing risks like infertility, bariatric surgeries and mental and psychiatric conditions and many more instigated substantial growth of Health insurance premium from Rs.24448 Crores in 2016 to Rs.44873, contributing an average of $21 \%$ every year.

\subsection{Status of Claims Ratios}

\begin{tabular}{|c|c|c|c|c|c|c|}
\hline \multicolumn{6}{|c|}{ Table:4, Comparison of Health Insurance Premium and Claims Ratios of Public and Private } \\
Companies \\
\hline Year & $\begin{array}{c}\text { Gross } \\
\text { Premium }\end{array}$ & Claims Paid & Claims Paid Ratio & Public Sector & Private Sector & $\begin{array}{c}\text { Stand- } \\
\text { alone }\end{array}$ \\
\hline $2009-10$ & 830518 & 745600 & 89.78 & 119.85 & 92.22 & 86.25 \\
\hline $2010-11$ & 1103050 & 1079700 & 97.88 & 106.31 & 85.15 & 67.82 \\
\hline $2011-12$ & 1304102 & 1228600 & 94.21 & 100.28 & 77.80 & 60.33 \\
\hline $2012-13$ & 1545295 & 1452600 & 94.00 & 103.21 & 79.08 & 61.36 \\
\hline $2013-14$ & 1749454 & 1697000 & 97.00 & 106.19 & 87.62 & 61.49 \\
\hline $2014-15$ & 2009622 & 1822293 & 90.68 & 109.97 & 79.17 & 66.06 \\
\hline $2015-16$ & 2444754 & 2175890 & 89.00 & 115.45 & 74.59 & 62.18 \\
\hline $2016-17$ & 3039171 & 2754598 & 90.64 & 120.15 & 74.70 & 56.47 \\
\hline $2017-18$ & 3702864 & 3024404 & 81.68 & 109.86 & 71.32 & 59.58 \\
\hline $2018-19$ & 4487276 & 3498282 & 77.96 & 107.12 & 75.85 & 61.00 \\
\hline
\end{tabular}

Source: IRDAI Annual Reports (2009-2019)

Incurred claims ratio is one of the essential metrics to know the financial strength of the Insurance Companies. The claims ratio or the incurred claims ratio is the value of the company's total claims against the total premium collected in that year. Hence, a low incurred claims ratio indicates the healthy growth of that portfolio. The ratio of less than 100 percent indicates that insurers are making a profit from that segment. From the above Table 4, it was observed that for the four public sector companies ${ }^{\text {iiii }}$ health business is a loss-making portfolio across all the years. The key reasons for increased claim ratios for public sector units are they undertake risky profiles and underwriting the majority of large group business, which covers corporate employees and their dependent family members.
There was a substantial reduction in the incurred claims ratio among the public sector companies from 119.85 to 106.31 in 2010-11; further, it reduced to 100.28 in 2011-12. All the time, private insurance companies are trying very hard to manage the claims ratios within 100 . The claims paid ratios of the private companies also reduced from 92.22 in 2009-10 to 77.80 in 201112. Between 2014 and 2016, all companies' overall claims paid ratios fell from 97 to 89 percent. This is due to a significant increase in the premium collection during that period from Rs. 17,494 crores to Rs. 24,448 crores. The higher growth rate in premium and reduced growth rate of claims has put a sizable surplus in insurance companies' hands. However, the public sector 
companies continue to experience higher claim ratios during this period also.

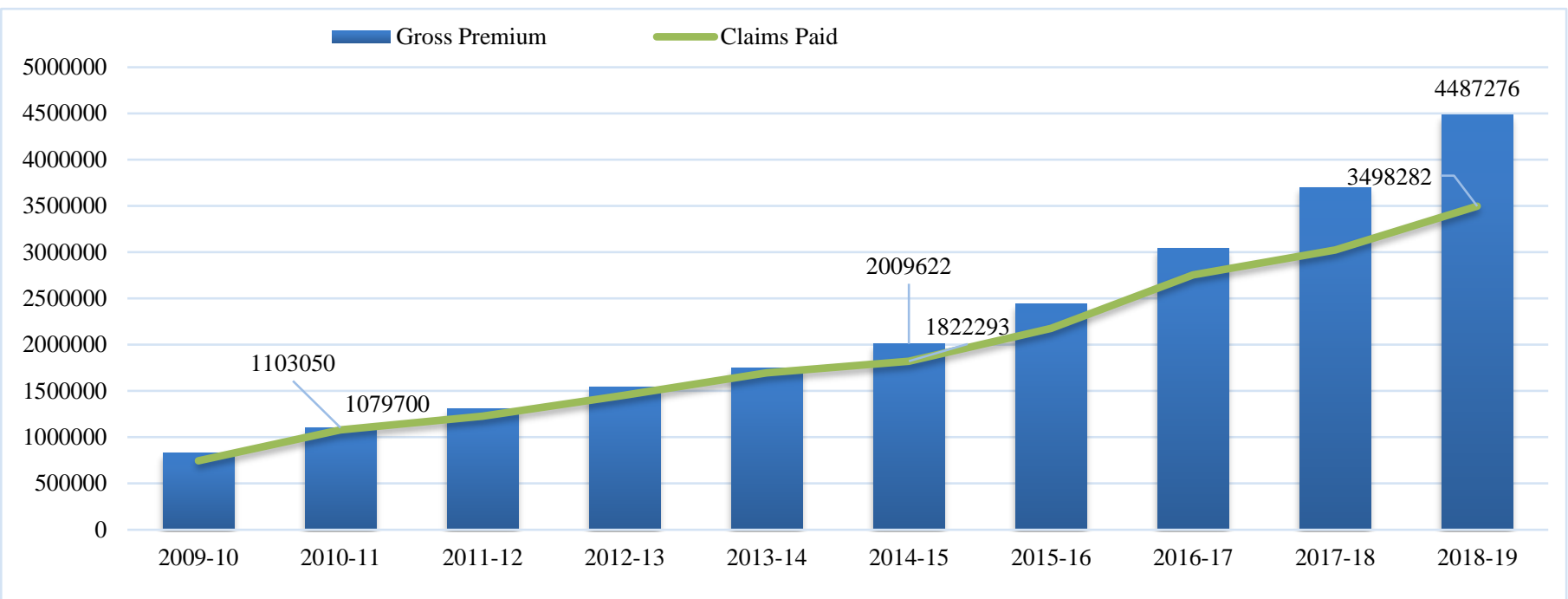

Figure 6. Premium collected vs. Claims Paid (in lakhs)

Source: IRDAI Annual Reports (2009 - 2019)

In the year 2016-17, the public sector companies experienced the highest incurred claim ratio, i.e., 120.15 percent among all the years till now. All the private insurance companies managed at the same level, around 74 percent, as in the previous year. Increased levels of pollution led to an increase in diseases and hospitalization expenses among the insured people ${ }^{\mathrm{iv}}$. The severity and frequency of communicable diseases have increased, resulting in increased claims ratios for insurers this yearv ${ }^{\mathrm{v}}$. During 2018-2019 the claim's ratios decreased from 81.68 and 77.96 percent, and consequently, the profit of health insurance companies also increased.

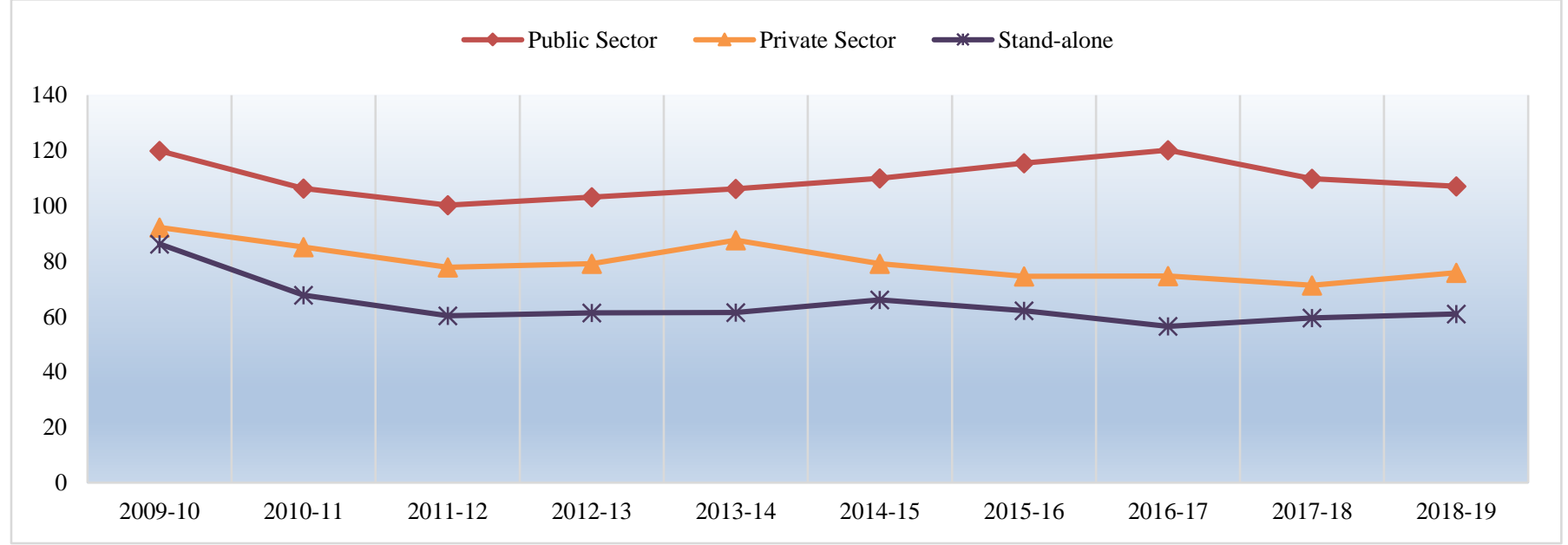

Figure 7. Incurred Claims ratios of Public vs. Private Insurance companies Source: IRDAI Annual Reports (2009 - 2019)

In the year 2006, Indian Insurance Regulator (IRDAI) took a path-breaking step by amending legislation to start a standalone health insurance company. As a result, the first standalone health insurance company Star Health and Allied Insurance, came into existence. Since its inception, Star Health has carved a niche for itself in health insurance, followed by the rest of the standalone insurers. The performance of standalone health insurance companies is remarkable in managing the claims ratios and achieving positive growth in the health insurance business.

\section{Way Forward}

Health insurance is certainly a growing segment, but the uninsured should be included in the insured population for further growth. Although 
several measures are taken at various levels to improve awareness and coverage, health insurance penetration is in single digits compared to matured countries (Insurance, 2017).

In India, most of the insurance companies' health plans take care of only inpatient expenses. Total insurance coverage in India is around 35 percent from public and private insurance companies, including Government schemes. In rural areas, out of the total health expenditure incurred by people, only a minute portion of expenses, i.e., 12.9 percent, are covered, and health insurance schemes do not cover a significant part, i.e., 85.9 percent of health expenditure. The situation is similar in an urban area, with 80.9 percent of the spending not protected. Government-sponsored schemes cover 8.8 percent, 3.8 percent is reimbursed under individual health insurance, and 3.3 by employer-paid insurance schemes (Government of India, 2019).

On the other hand, most insurance companies do not cover outpatient expenses (Medicines and consumables) in their policies; thus, Out Of Pocket expenditure has increased (Karan, Yip, \& Mahal, 2017). Hence it is evident that these are the main reasons for rising Out Of Pocket expenditure towards health care. However, health insurance premium has significantly increased in the post-liberalization period. The above statistics indicate that insurers need to revise the policy's scope as per the policy holder's requirement.

Proactive regulations in the recent past by IRDAI have stirred health insurers to deal with wellness and health coach programs to strengthen the segment. Digital interventions will change the health insurance business landscape in the coming years (Yenkataraman; \& Kothamasu, 2018). The introduction of automation in various health insurance areas will improve business profitability and enhanced customer experience. Smart cards' implementation in the health insurance schemes facilitated multi verification and helped the industry prevent frauds. Rashtriya Swasthya Bima Yojana (RSBY), a health insurance scheme introduced in 2008 for people living below the poverty line across Indian states, is the best example for many technological interventions. This scheme successfully implemented a biometric accessible smart card with Rs. 30,000/coverage amount being loaded and can operationalize the paperless scheme with the help of technology. The scheme aimed to control fraud and monitored utilization by implementing online submission of claim forms and direct settlements with hospitals(Maitra, 2017). The new ambitious health insurance scheme introduced by the Government of India, referred to as Ayushman Bharath, has built-in both concepts of wellness and technology interventions. Ayushman Bharath has two components, Health and Wellness Centers (HWCs), which are aimed at providing comprehensive primary health care and secondly, Pradhan Mantri Jan Aarogya Yojana (PM-JAY) which provides health insurance cover of Rs.5 lakhs per year to poor and vulnerable families. As this scheme offers a considerable amount of health cover of Rs.5 lakhs, whereas the average medical expenditure per hospitalization is Rs.20,135 ${ }^{\mathrm{vi}}$ in India, there will be a huge opportunity for fraud in the form of producing inflated medical bills. However, implementing online submission and automation processes with the help of the latest tools like Big data, Artificial Intelligence, and Machine Learning can reduce such types of fraud(Capgemini, 2019).

Insurance companies are now shifting their focus towards Wellness concepts which are designed to improve individual health through proper diet, exercise, stress management, and illness prevention. It may include fitness challenges, smoking/drinking cessation, relaxation therapies, and many other programs to increase an individual's overall health. These programs are encouraged by physicians, Insurers, employers to reap the long term benefits of staying fit and healthy(Pwc and FICCI, 2004).

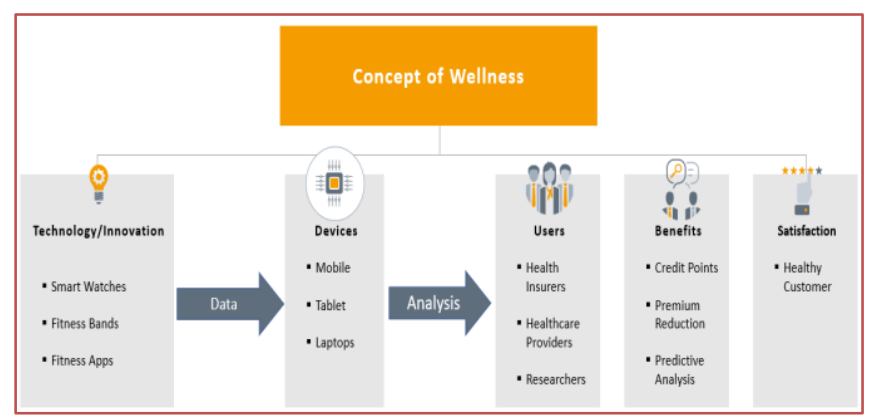

Figure 8, Benefit illustration - Concept of Wellness

Source: Author's work

any health insurers are rewarding their policyholders by offering reductions in premiums for following wellness measures. Insurers are also encouraging their clients to wear smartwatches 
and fitness bands. Through these wearables, insurers can gather relevant data to improve their risk decisions, as shown in Figure 7. The sensorbased devices will help insurers to underwrite better risks based on the real-time data. It will further provide a lot of information to researchers to analyze further dangers of diseases and help in prevention.

\section{Conclusion}

The growth of health insurance after privatization is noteworthy. Premium collected by Insurers is remarkable and has increased from Rs. 761 crores in 2001 to Rs. 50834 crores in 2019, indicating growth of 66 times over the 20 years. The claim paid out ratios have improved and remained below 100 for all the standalone health insurers and private insurers. Public sector companies are steadily growing and also balancing their claims ratios. Overall, both the premium collection and claims ratios have shown significant improvement over these years. Proactive Regulations helped strengthen the sector, especially after 2013, and contributed majorly to the segment's growth. The rise in the cost of health care, the uncertainty of diseases and treatments, increased awareness among the public, Government focus on providing quality health care, etc. show the great scope for expanding health insurance in the coming years.

As a sustainable approach, health insurers should establish long-term relationships with the customers to improve processes and products in the long run. The introduction of automation of various processes aims to reduce fraud in the segment and show positive growth in the coming years. The concept of wellness has just been introduced in the Indian market, and there is a long way to go. Technology should support to take forward the idea of wellness in mixing with the primary health insurance product. The health insurers are moving on to the next level, motivating customers to keep themselves healthy and lead good lives.

\section{References}

[1] Ahlin, T., Nichter, M., \& Pillai, G. (2016). Health insurance in India: What do we know and why is ethnographic research needed. Anthropology and Medicine, 23(1), 102-124

[2] Anita, J. (2010). Emerging Health Insurance in India - An overview. 10th Global Conference of Actuaries, 81-97
[3] Capgemini. (, 2019). World Insurance Report. Capgemini and Efma

[4] FICCI, K., and. (, 2017). Health savings account in India, (December)

[5] FICCI, P., and. (, 2004). Riding The Growth Wave. Dataquest, 22(14), 17-30

[6] Government of India. (, 2019). Key indicators of social consumption in India: Health. National Sample Survey Organisation

[7] Insurance, M. G. (2017). Global Insurance Industry Insights An in-depth perspective

[8] IRDAI. (2018-19). IRDAI 2018-19

[9] IRDAI. (2017-18). IRDAI Annual Report, 2017-18

[10] IRDAI. (2015-16). IRDAI Annual Report 2015-16. Annual Report (Vol. 53)

[11] Jayakrishnan T, Jeeja MC, K. V. and P. S. (2015). Increasing Out-Of-Pocket Health Care Expenditure in India-Due to Supply or Demand?

[12] Joglekar, R. (2008). Can Insurance Reduce Catastrophic Out-of-Pocket Health Expenditure? Rama Joglekar Can Insurance Reduce Catastrophic Out-of-Pocket Health

[13] Karan, A., Yip, W., \& Mahal, A. (2017). Extending health insurance to the poor in India: An impact evaluation of Rashtriya Swasthya Bima Yojana on out of pocket spending for healthcare

[14] KPMG and OPPI. (, 2016). Report on healthcare access initiatives. KPMG and OPPI Report on Healthcare Access (August)

[15] Mahapatro, S. R., Singh, P., \& Singh, Y. (2018). How effective health insurance schemes are in tackling the economic burden of healthcare in India. Clinical Epidemiology and Global Health

[16] Maitra, S. (2017). A Use Case of Smart cards in Rashtriya Swasthya Bima Yojana. Ijetsr, Volume 4(August)

[17] Sangar, S., Dutt, V., \& Thakur, R. (2019). Economic burden, impoverishment, and coping mechanisms associated with out-ofpocket health expenditure in India: A disaggregated analysis at the state level. International Journal of Health Planning and Management,

[18] Shah, A. Y. and. (, 2014). Growth of Health Insurance Sector Post Liberalisation in India, $I V(\mathrm{I})$ 
[19] Yenkataraman, S. S. K., \& Kothamasu, R. (2018). Top 10 Technology Trends in Health Insurance : 2018 What You Need to Know. Health Insurance Trends, Capgemini

[20] D.Chennappa (2015). Impact of Private Insurers' participation in Health Insurance Business in India. The Journal of Insurance Institute of India

\footnotetext{
${ }^{\mathrm{i}}$ As per poverty line setup by Planning Commission of India ii As per world bank data,2016

iii National Insurance Co.Ltd, New India Assurance Co.Ltd, Oriental Insurance Co.Ltd, United India Insurance Co.Ltd

iv Communicable diseases are illnesses caused by viruses or bacteria that people spread to one another through contact with contaminated surfaces, bodily fluids, blood products, insect bites, or through the air.

${ }^{v}$ Communicable diseases are illnesses caused by viruses or bacteria that people spread to one another through contact with contaminated surfaces, bodily fluids, blood products, insect bites, or through the air.

vi Key Indicators of Social Consumption in India, 2018, Government of India.
} 